\title{
Las palabras vuelan, los escritos permanecen'
}

\author{
FEDERICO MAYOR ZARAGOZA \\ (Fundación Cultura de Paz) \\ España
}

Recuerdo las primeras lecturas en el colegio "Virtelia" -traducción obligada al castellano de "Blanquerna"- que me permitieron descifrar aquellos signos mágicos que, en todas las lenguas, convertían en voces y expresiones, en palabras, los sentimientos, pensamientos, imaginaciones.

En 1940, cuando tenía seis años, hablábamos en casa el catalán, en la rica variante tortosina, del bajo Ebro. En la escuela, sólo en los momentos de clase, el castellano. Pronto se añadió el francés. La "mademoseille" nos mostraba ágilmente las similitudes y diferencias entre las tres lenguas de raíces latinas. Se escribía de una manera y se pronunciaba de otra. En I946, empecé a estudiar el inglés en el "British Council”, de Barcelona. Entonces comprendí la extraordinaria importancia de aprender muchas lenguas lo antes posible. Los niños incorporan palabras como respiran. Luego, más tarde, el aprendizaje es ya comparativo y más difícil.

Mi madre, de modesto origen y una fantástica capacidad intelectual, quería que tuviésemos consciencia permanentemente de lo que nosotros teníamos y sabíamos en relación a lo que tenían y sabían los otros niños, cercanos o distantes, de tal modo que apreciásemos mejor lo que poseíamos y conociéramos las capacidades y precariedades ajenas. Pensaba en los niños de tantas partes del mundo que no sabían leer

que no podían leer...

Pensaba en tantos siglos de tanta gente sin conocer otros pensamientos que los propios y los de la gente de su entorno... ¡Cuántas reflexiones, cuántos sonidos... fugaces, perdidos para siempre! ¡Qué suerte poder compartir la riqueza inmensa de tanto saber acumulado, de tantas ideas expresadas de forma indeleble!

Me impresionó lo que me contó años más tarde el senegalés Amadou Mahtar M'Bow, mi antecesor en la Dirección General de la UNESCO: “Todo su pueblo era palabra. Todo su pasado estaba en la voz. Nadie más que él sabía la fuerza del lenguaje. Lo que debía hacer, lo que hicieron sus antepasados, los nombres de las cosas, la forma de orientarse y de reconocer las hierbas buenas de las malas... todo era verbo, todo se contenía y conservaba y transmitía oralmente. Toda referencia estaba sólo en la memoria. Él lo sabía y procuraba

\footnotetext{
I Para citar este artículo: Mayor Zaragoza, F., Las palabras vuelan, los escritos permanecen. Álabe 4, diciembre 20 II [http://www.ual.es/alabe]
} 
recordar cuanto escuchaba contar a los ancianos que desgranaban sus recuerdos para que los demás los retuvieran, y a los viajeros llegados al poblado que referían las costumbres de otros países...

También nosotros deberíamos poder encerrar nuestras palabras en signos y guardar todo lo que retenemos, sabemos y pensamos en los anaqueles de nuestras casas, para que lo conozcan los hijos de nuestros hijos, para que podamos hacer llegar de forma perenne nuestro mensaje, como practican desde tiempo inmemorial otras culturas. ¡Poder comunicarse con los demás sin estar cerca en el espacio y en el tiempo, poder transmitir a multitudes lo que él se esforzaba en acumular para unos cuantos!.. Pasados algunos años, elaboró el abecedario, la caligrafía y la gramática de su lengua, sobre la base de las normas y rasgos propios de la escritura de la nación colonizadora, del francés. Más adelante conoció países en los que las palabras se plasmaban en ideogramas, en caracteres que evocaban lo que pretenden representar. Miles de formas que recogían en sus trazos no sólo la palabra, sino su acento, su vigor, su movimiento o su fuerza. En la escritura, en cualquiera de sus modalidades, se cumplía lo que él tanto anhelaba para su propia lengua, lo que decía Han Iu acerca de Zang Xu: “Conserva todo en su visión: paisajes, animales, plantas, astros, tormentas, incendios, guerras, festines, todos los acontecimientos del universo, ,... y los expresa a través de su arte”.

El pasado de grandes civilizaciones llegaría así hasta nuestros días vigoroso, recién hecho, caudaloso. El futuro de su civilización, cuyo eco tenue no reflejaba ni su antigüedad ni su grandeza, se asentaría en la escritura. El futuro de su pueblo, como el de los otros pueblos, radicaba en el libro. En los libros que hubiera en las estanterías y en las repisas de las casas, en las bibliotecas y en las escuelas. Con la escritura, había abierto la besana más fructífera y esencial para el porvenir de su tierra, de los suyos ${ }^{2}$.

Otro sabio africano, Mpate Ba, exclamó en el Consejo Ejecutivo de la UNESCO: "En África, cuando un viejo muere una biblioteca se quema".

Dar valor a lo que tenemos, ser capaces de vencer la monotonía, la rutina, apercibiéndonos de las cosas esenciales, de los pilares, de las piedras angulares. "Es muy infrecuente observar lo que vemos todos los días”, decía Julián Marías.

Palabras, frases que dejan huella. Referencias que se instalan en nuestro firmamento, como luces permanentes para guiar el comportamiento cotidiano. Como ejemplos, cito las siguientes:

\footnotetext{
${ }^{2}$ Escrito para la obra "La cultura del libro", coordinada por Fernando Lázaro Carreter (I983).
} 
- A finales de la década de los cuarenta, leí en un libro de Albert Camus: “Les despreciaba, porque pudiendo tanto se atrevieron a tan poco".

- De Miguel Hernández: "Me duele este niño hambriento como una grandiosa espina".

- De Salvador Espriú: "Los hombres no son si no son libres".

- De Miquel Martí i Pol: "El futuro está por hacer y todo es posible... pero, ¿quién, si no todos?".

- De Edmund Burke: “iQué pena que pensando que puedes hacer poco no hagas nada!”.

He tenido la ocasión el honor y la ocasión de conocer personalmente y contar con la amistad sincera de grandes escritores contemporáneos, Premios Nobel de Literatura: Wole Soyinka, José Saramago, Gabriel García Márquez. De todos ellos aprendí escuchando. De todos ellos puedo seguir aprendiendo al leerlos. Sus escritos son presencia permanente, mensajes lúcidos dirigidos a un mundo que hoy, más que nunca, necesita apropiarse del tiempo necesario para la reflexión, la escucha, la lectura.

¡Leer ... y escribir! Escribí libros de ensayo: desde "Mañana siempre es tarde”, en I984, hasta "Delito de silencio", en 2oIr. Y de poemas: desde "A Contraviento" (I968) hasta, hace unos días, "Donde no habite el miedo", diálogo poético con María Novo. Poemas escritos en muchos sitios, dedicados algunos a personas que han influido decididamente en mi vida. Al Presidente Nelson Mandela, en mayo de ig88, al cumplir los 7o años, 26 ya en prisión por el único delito de haber nacido con la piel morena, le escribí: "Ahí estás, aherrojado, / dándonos libertad / a manos llenas. / Queremos hoy que sepas / que nuestras alas / tienen en cada pluma / la marca de tus rejas; / ... Que desde tu celda / liberas y excarcelas / a tanto corazón anclado / en la tibieza..."3.

En Dhaka, Bangladesh, escribí en noviembre de 1997: “Deber de memoria / cuando todo clama olvido; / cuando el viento / se detiene en los olivos / y el apremio del presente / nubla los ojos / y la mente; / cuando la prisa / de cada instante / que vivimos / nos induce / a intentar evadirnos / del recuerdo..."4.

Y, más recientemente: "Que el miedo / no paralice tu fuerza / inmensa, distintiva, / de crear, de rebelarte, / de transitar por nuevos puentes / y llenar de palabras de paz los himnos de guerra. $/ "$ "

\footnotetext{
3 En “Aguafuertes”, I99I.

4 En “En pie de paz”, 2008.

5 "En donde no habita el miedo", 2 OII.
} 
No quiero terminar este resumen de escritos que se han convertido en balizas para mi despegue cotidiano, sin mencionar a dos poetas contemporáneos que han tenido una especial capacidad de orientación, de llamar a rebato a nuestras mentes tantas veces adormecidas: me refiero a José Ángel Valente y a Pedro Salinas. Del primero, extraigo de "Sobre el tiempo presente", un fantástico poema, esperanza en la zozobra: "Escribo desde un naufragio. / ... Escribo sobre la latitud del dolor, / sobre lo que hemos destruido / ante todo en nosotros, ... / Escribo desde la noche, / desde la infinita progresión de la sombra / desde el clamor del hambre y del trasmundo, / desde la mano que se cierra opaca / desde el genocidio, / desde los niños infinitamente muertos, / desde el árbol herido en sus raíces... / Pero escribo también desde la vida, / desde su grito poderoso, / escribo, hermano mío, de un tiempo venidero...".

De Pedro Salinas, la enseñanza del deber supremo de seguir, de no rendirse, de intentar hallar respuestas: "Nos llenará la vida / este puro volar sin hora quieta... / en esa luz lenta y segura / con se conocen letras / y formas...".

Sentir, escuchar, meditar, inventar, prever... haciendo uso de las facultades distintivas de la especie humana, "ojos del universo". Describir lo que he visto, lo que he sentido como estudiante, como profesor, como rector de universidad, como investigador científico... Compartí la imborrable emoción que me produjo la visita, en I956, a un centro de niños con deterioro mental irreversible. Unos años más tarde, iniciaba, como reacción a aquellos profundos sentimientos, la puesta en marcha del Plan Nacional de Prevención de la Subnormalidad...

El conocimiento profundo de la realidad es absolutamente imprescindible para un científico, que sabe que sólo si conocemos en profundidad podemos transformar en profundidad. Y visión prospectiva para vencer la inercia, siendo capaces de acelerar la evolución conservando lo que tiene valor intemporal y cambiando todo aquello que con el paso del tiempo ha devenido inadecuado y anacrónico. Saber para prever, prever para prevenir: recuerdos de diputado en el Congreso y en el Europarlamento ... “iparlare”!... Sí, hablar, hablar y hablar porque la gran transición es, precisamente, la de la fuerza a la palabra, la de la mano armada a la mano tendida, la de la imposición al encuentro, al diálogo, a la conciliación.

Una de las vivencias más importantes de mi vida ha sido el conocimiento y el aprecio de la labor crucial de los maestros, de los profesores de todos los grados, pero sobre todo de la educación infantil y primaria. Además de mis “maestros naturales" -el ejemplo de perseverancia e imaginación de mi padre y de las recomendaciones de mi madre que han pasado a formar parte constante de mi vida ("descansa lo justo y duerme lo indispensable: ya descansaremos cuando nos muramos"; "No aceptes nunca lo que creas que es inaceptable"......- han quedado grabadas de forma indeleble en mi mente las pautas, 
recomendaciones y, sobre todo, los ejemplos de mis maestros de quienes, a lo largo de mi vida, han sido "mis" docentes,... Mi admiración a quienes, supliendo la labor propia de los progenitores en muchos casos, dedican su vida a la educación, a procurar "seres humanos libres y responsables", "capaces de dirigir con sentido la propia vida”, según la magistral definición de la educación de D. Francisco Giner de los Ríos.

Son los maestros los grandes artífices del lector. Lo sé bien como Ministro de Educación y Ciencia y como Director General de la UNESCO, atalaya desde la que he podido contemplar tantas cosas bellas, tantas tragedias, tantos olvidos, tantas asimetrías y desgarros sociales... que me han llevado a dedicar los últimos años de mi trayectoria humana a la cultura de paz, a hacer todo lo posible para que no miremos hacia otro lado, a promover actitudes solidarias, que debemos muy especialmente a los jóvenes que llegan a un paso de nosotros. No es posible conciliar el sueño cuando cada día mueren más de 6o.ooo personas, en un genocidio de desamor y desamparo, mientras que nosotros, los habitantes del barrio próspero de la aldea global, seguimos, progresivamente uniformizados, preocupándonos exclusivamente por "lo nuestro”...

La transición desde una cultura de imposición, violencia y guerra a una cultura de conversación, alianza y paz no se logrará a través del cambio de sistema económico, que es urgente e imprescindible, sino, sobre todo, a través de un cambio de conducta, de cultura, de comportamiento diario. La gran transición, ya lo decía antes, es la de la fuerza a la palabra. La esperanza se acrecienta hoy, precisamente, por la capacidad de la participación no presencial, por la expresión sin límites que nos permite la moderna tecnología de la información y de la comunicación.

Actualmente, los conocimientos pueden almacenarse en ingenios informáticos que permiten un fácil y rápido acceso; otros medios de comunicación transmiten continuamente atractivos programas a través de los sistemas audiovisuales... pero el libro permanece inmutable como el supremo vínculo de unión entre los tiempos, los espacios y las personas. Porque el libro no se contempla u oye. El libro se reescribe. El lector es coautor y no receptor pasivo.

"Libros, muchos libros y muchas lenguas... muchas lenguas y muchas hebras para este tejido multicolor y tupido como la realidad misma. Los libros leídos, acotados, comentados, son como un eco, como un testimonio, como una llamada permanente que orienta, especialmente en momentos de cambios. Sin libros, muchos libros, mi vida no habría sido como ha sido. Habría carecido de los asideros que tanto se necesitan cuando más oscura es la noche".

La voz frente a la palabra, la palabra frente a la espada. Tened siempre cerca un libro; dejad siempre un poco de tiempo para leer. Quizá así no necesitaréis alas prestadas y sa- 
bréis discernir mejor lo que os conviene. Lo importante es razonar, pensar. La gimnasia física refuerza los músculos. La lectura, la capacidad intelectual, la facultad creadora. Sin libros, sin espacio y tiempo para leer, pensar y comunicar, no será posible encarar los desafíos presentes. No será posible deshacer unos nudos gordianos que ya no pueden, como hizo Alejandro Magno, cortarse con la espada.

Rodeados de artificios, de productos inventados, para que nosotros inventemos menos, nos van expropiando nuestro espíritu, nos van minando nuestra "mismedad" como decía Xavier Zubiri, nuestro perfil cultural, nuestros hábitos... hasta llegar al apogeo del "consumidor ejemplar”, que viste, calza, come, se peina, actúa, habla y siente... como le impone la moda, pero que, de pronto, se da cuenta, de su mente huera, de su vacío interior. Como en el poema de Jesús Massip, "las horas han vuelto y nos han encontrado instalados y dóciles". Que las horas vuelvan y nos hallen siempre alerta, al justo filo de las sombras y las luces, que es donde se halla la libertad y la fuerza creadora" ${ }^{6}$.

Las bibliotecas del mañana no sólo contendrán, ciertamente, libros y todo tipo de información digital, sino que, junto a escritos originales, figurarán los que "nacieron digitales" para ser después editados. En una palabra no sólo se “digitalizarán” libros sino que se “publicarán” textos digitales.

"Libro y lectura para favorecer la ciudadanía global. El libro es esencial para promover, entrenar, desentumecer nuestra facultad esencial, para que el comportamiento humano no responda al dictado de nadie sino al de la propia conciencia, resultante de la reflexión. Escuchar y leer son dos pilares sólidos para forjar actitudes propias de la conducta "deliberada”, consciente. La lectura proporciona independencia, autonomía, inquietud, curiosidad, capacidad de formular preguntas empezando por las dirigidas a uno mismo"7.

Lectura para transformar muchos imposibles hoy en posibles mañana. Lectura para, progresivamente, ser muchos los ciudadanos plurilingües, diversos, con visión global, conscientes de sus responsabilidades, capaces de convertir sus anhelos, desde la zozobra actual, en realidad, para hacer posible la inflexión histórica que ya se vislumbra: la conversión de súbditos en ciudadanos plenos, participativos, para la construcción, a escala global y local, de la democracia genuina. El tiempo del silencio ha concluido. El siglo XXI será, por fin, el siglo de la gente.

\footnotetext{
${ }^{6}$ Pregón en la presentación de la Feria del Libro de Madrid 2002.

${ }^{7}$ En "Lectura, sociedad civil, ciudadanía global”, Instituto de España, 2008
} 